\title{
A Dual Cutting Edge for A Single Tool Shaper Machine
}

\author{
Budarapu Pranav \\ Dept of Mechanical Engineering, \\ Sreenidhi Institute of Science and Technology, \\ Hyderabad, Telangana, India.
}

\begin{abstract}
In the era of rapid production field in industries there were n.no of machines in which some are dependently and some independently work together to fullfill the needs of the customer, there were many reciprocating machines which are under the performance of removing the excess material or to design the requried shape of the material.

A shaper is a type of machine tool that uses linear relative motion between the workpiece and the cutting tool which removes the material by the tool movement which carries the motion i.e.. (to and fro) now we are introducing the same shaper machine with an advanced one, in order to increase the rate of production and to decrease the unit time requried to operate the workpiece by the previous type shaper machine.
\end{abstract}

\section{INTRODUCTION}

In general the shaper machine consists of a single point cutting tool where the removal of the material takes place in the forward stroke of the tool and the return stroke does not perform any cutting action due to the presence of cutting edge in the front portion of the tool,to achieve this, the cutting tool which is mounted over an arrangement of a clapper box ,in which to utilise the return stroke we are replacing the tool and the clapper box with only a tool consisting of two cutting edges opposite to each other i.e.., front as well as back for this we are replacing the mechanism with crank and slotted lever mechanism which accurately fixes the machine to perform the action on both the forward as well as backward stroke.

\section{DUAL EDGE SHAPER TOOL WORKING MECHANISM:}

The work piece is mounted to the bench vice where the dual edge single tool mounted to the tool post with the absence of clapper box while the movement which takes places by the ram is carried out by slider crank mechanism which converts the rotary motion to the linear motion where the ram is positioned or connected in the place of slider which guides the to and fro movement.in this process the forward stroke and the return stroke of the tool comes into an action with the work piece as the feed is possed by the worker to the tool post with the intervals of the cutting as the tool moves forward the tool cuts the material by the front cutting edge and moves forward slightly at this time the worker has to posses a fees to the tool as the ram returns again in the return stroke the tool having an another cutting edge for the same tool opposite to each other cuts the materials as the process goes on the spees of the ram is regulated by the gears or speficed rpm

\section{SLIDER CRANK MECHANISM}

Slider crank mechanism is defined as the simplest mechanism which converts the rotary motion of a body to a reciprocating motion or vice versa. In this machine the slider part of the mechanism is directly coupled to the ram of the shaper machine as the gears are connected to the slider using pulley, while pulley is in rotary motion the motion is carried to the slider by the connecting rod so that the sider moves to and fro as we mentioned in the above cutting action takes place.

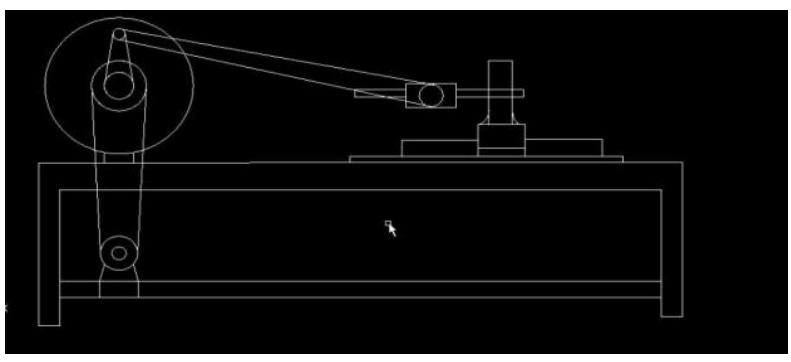

Parts of above fig. 1

1 .crank

2 .motor

3 .work holding device

4. cutting tool

5. slider rod

6. connecting rod

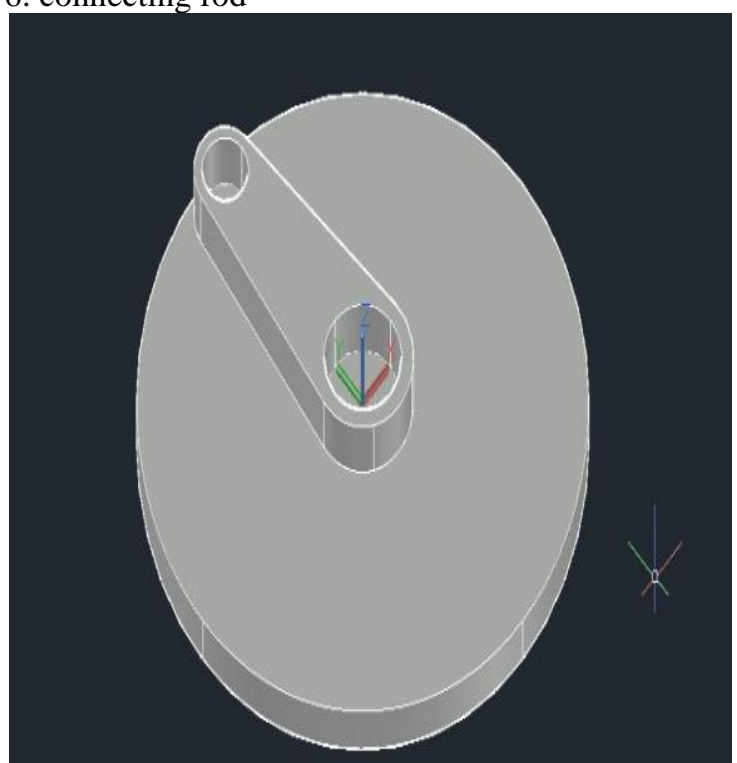

A. Crank case 


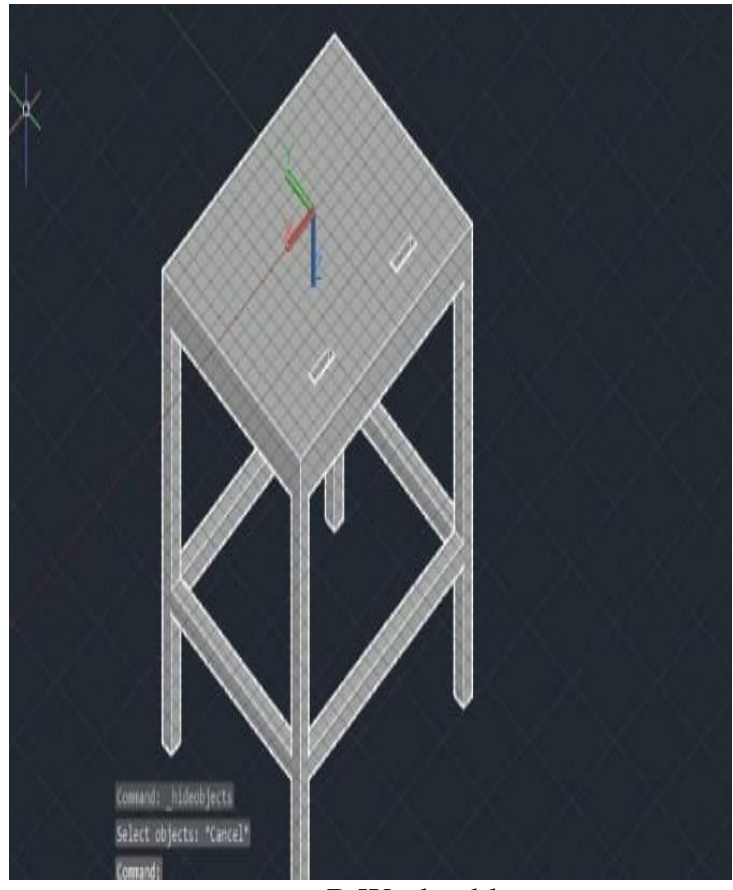

B.Work table

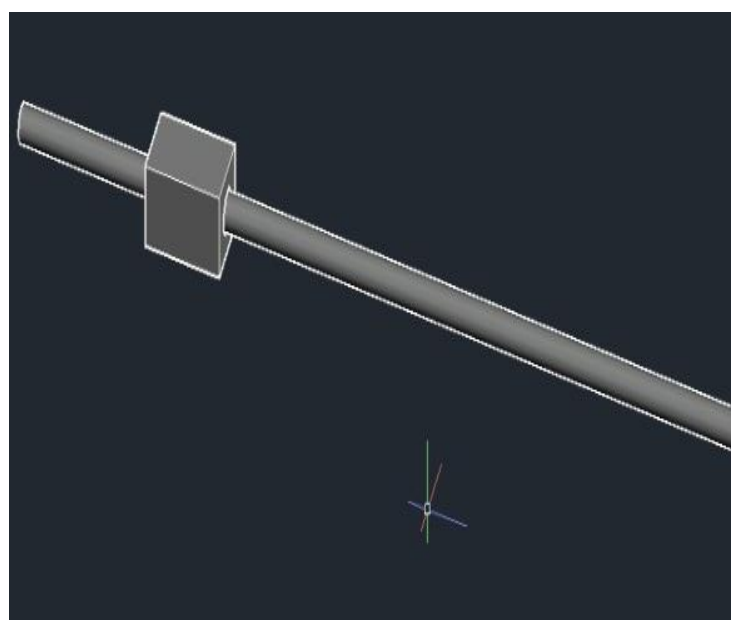

C.Slider

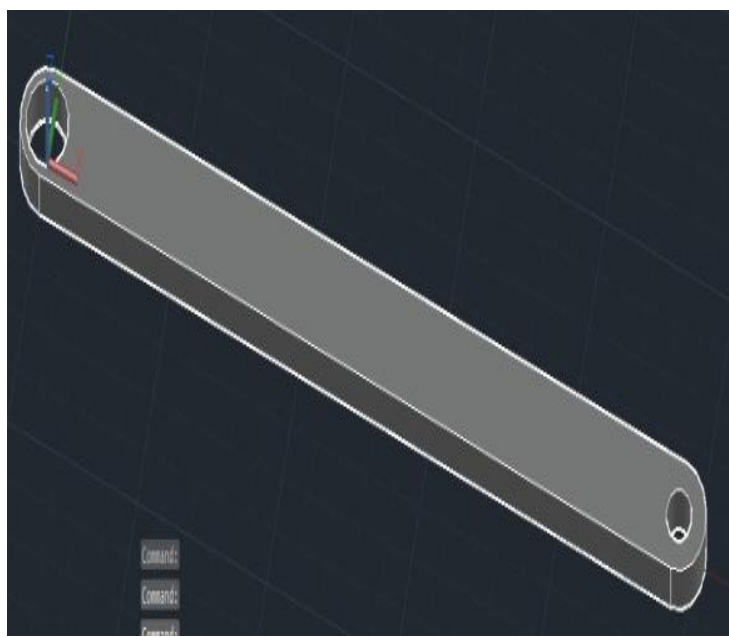

D.rod with u-shaped hook

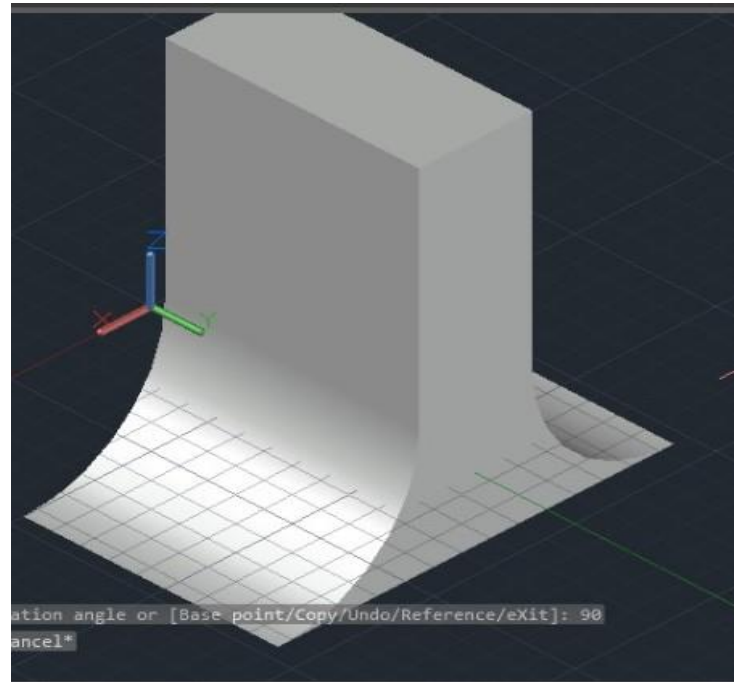

E. work tool

MODEL FIGURES DESIGNED IN SOFTWRE:

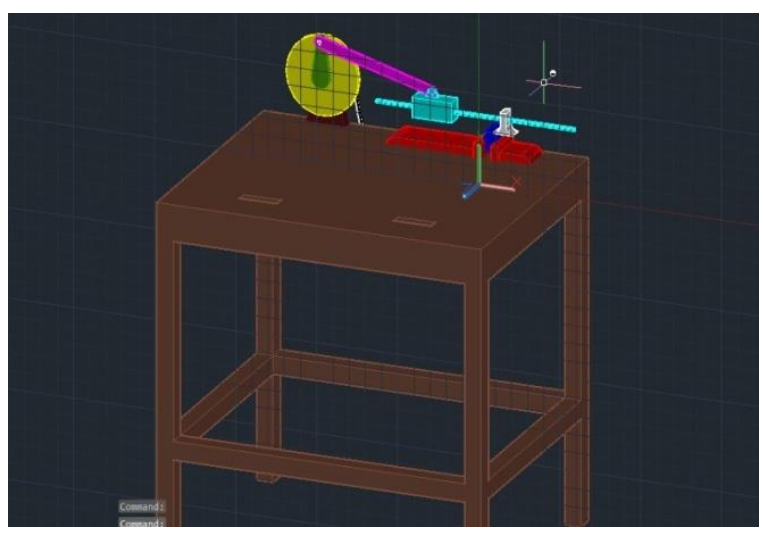

B.

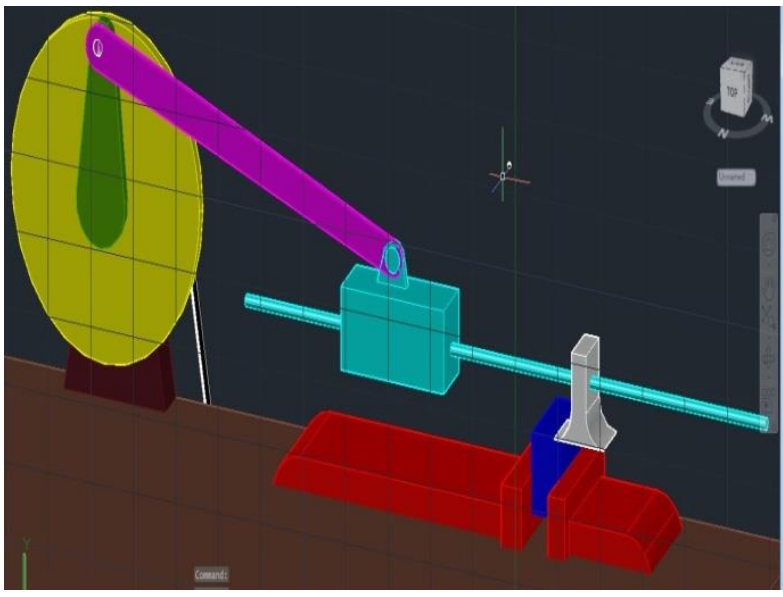

C 


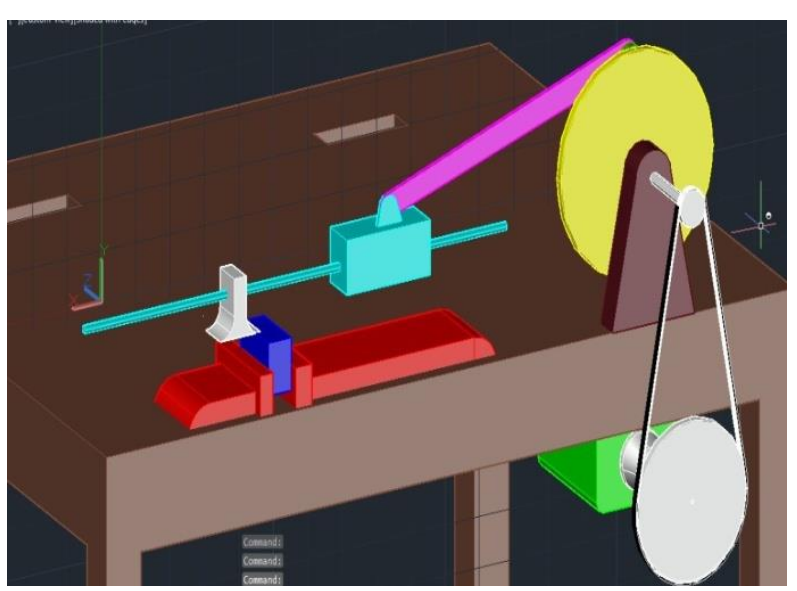

Some of the related machines list are;

\begin{tabular}{|l|l|}
\hline MACHINES & OPERATIONS \\
\hline Welding machine & Welding (arc) \\
\hline Drilling machine & $\begin{array}{l}\text { Boring, drilling, counter sunk, } \\
\text { counter boring }\end{array}$ \\
\hline Grinding machines & Grinding(surfaces, tools) \\
\hline Milling machine & End milling, back milling \\
\hline Metal cutting machine & Cutting operations \\
\hline
\end{tabular}

\section{CALCULATIONS:}

Figure out the maximum time required to the complete the job of:

Width $=20 \mathrm{~mm}$

Depth of work piece to be cut $=10 \mathrm{~mm}$

Length of stroke $=250 \mathrm{~mm}$

Length of full stroke $(\mathrm{N})=245 \mathrm{~mm}$

Feed $=0.5 \mathrm{~mm}$

Cutting speed $(\mathrm{Vc})=(2 * \mathrm{~L} * \mathrm{~N}) / 1000$

$\mathrm{Vc}=(2 * 250 * \mathrm{~N}) / 1000=122.5 \mathrm{~m} / \mathrm{min}$

Time taken to complete one full stroke = $(2 * \mathrm{~L} * 60) /(1000 * \mathrm{Vc})$

$=(2 * \mathrm{~L} * 60) /(1000 * 122.5)=0.2448$

Total time taken for one complete stroke $=(\mathrm{w} / \mathrm{f}=100)$

Total time for one stroke $=0.2448 * 100=24.48 \mathrm{sec}$

Total number of strokes required to cut $10 \mathrm{~mm}$ depth slot $\mathrm{T}=\mathrm{Tc} * \mathrm{n}$

$\mathrm{T}=24.48 * 20\left(\mathrm{n}=\right.$ feed $^{*}$ depth of cut $\left.=0.5 * 10=20\right)$

$\mathrm{T}=8.16 \mathrm{~min}$

Comparing to the older machine our new shaper machine has a better working facility to reduce the time, so that 1.cost of labour and some allowances are reduced to the company this helps to increase the profits. As well as to increase the productivity of the products
By this modified machine the time required for producing a product will reduce so that there is a chance of more time to produce the products for fulfilling the needs of the customer more and easily .

\section{EXISTING SHAPER MACHINE :}

Full stroke $=$ forward stroke + return stroke

Time taken for the forward stroke in the existing

shaper machine $=0.287$

Time for return stroke $=0.0917$

Total time $=$ forward stroke + return stroke

Total time $=0.287+0.0917=0.3787$

Total time $=0.3787 * 100=37.87 \mathrm{sec}$

Time required for single complete stroke $=37.87 \mathrm{sec}$

For completion of $10 \mathrm{~mm}$ depth slot it takes $=37.87 * 20 / 60$ $=12.62 \mathrm{~min}$

The amount of time saved by the modified shaper machine s compared to the older one is $36 \%$

\section{RESULT AND DISCUSSIONS:}

Dual cutting edge shaper machine resembles like holding two cutting tools to a single shaper machine tool, hence the machine occupies less time to finish the job no of equipments are reduced to hold the other cutting edge tool so, that the cost of equipments tohold are reduced as well as the time required for machining the workpiece are reduced the cost of labour as well as the cost of power required to drive the machine are reduced up to $36 \%$.ascompared to existing shaper machines .

\section{REFERENCES}

[1] M.V.N srujan manohar, international journal of engineering research and technology(IJERT) volume 1, Issue 6, august2012

[2] R. maguteeswaran, international journal of research in aeronautical and mechanical engineering, volume 2, issue 2 , feb- 2014.

[3] Devanand R.Tayade, International Journal of Innovative Research in Advanced Engineering (IJIRAE), Volume 1, Issue 6, July2014.

[4] Deepak Lathwal, International Journal for Research In Applied Science and Engineering Technology (IJRASET), Volume 1, Issue 1, Aug-2013.

[5] S. Sundaram, ARPN Journal of Engineering and Applied Sciences, Volume 3, No. 4, Aug-2008.

[6] Junwei CHENG, Journal of Software, Volume 6, No. 1, Jan2011. A Textbook of Manufacturing Technology-I, Pakirappa2012 